\title{
PREVALENCE OF SENSORINEURAL HEARING LOSS IN TYPE 2 DIABETIC SUBJECTS AND ITS CORRELATION TO GLYCAEMIC STATUS AND DURATION OF DIABETES MELLITUS
} Arun Kumar $S^{1}$, Babu $R^{2}$, V. Sakthivel ${ }^{3}$, Shigil Mathew Varghese ${ }^{4}$, Nikil Sam Varughese ${ }^{5}$, Joga Veerabalaji6, Rajashekar Reddy T. V7,
Premnath $V^{8}$

${ }^{1}$ Assistant Professor, Department of General Medicine, Vinayaka Mission's Medical College and Hospitals, Karaikal. ${ }^{2}$ Assistant Professor, Department of General Medicine, Vinayaka Mission's Medical College and Hospitals, Karaikal. ${ }^{3} H O D$, Department of General Medicine, Vinayaka Mission's Medical College and Hospitals, Karaikal.

4 Post Graduate Student, Department of General Medicine, Vinayaka Mission's Medical College and Hospitals, Karaikal.

5 Post Graduate Student, Department of General Medicine, Vinayaka Mission's Medical College and Hospitals, Karaikal.

${ }^{6}$ Post Graduate Student, Department of General Medicine, Vinayaka Mission's Medical College and Hospitals, Karaikal.

7 Post Graduate Student, Department of General Medicine, Vinayaka Mission's Medical College and Hospitals, Karaikal.

${ }^{8}$ Post Graduate Student, Department of General Medicine, Vinayaka Mission's Medical College and Hospitals, Karaikal.

\section{ABSTRACT}

\section{OBJECTIVE}

1. To record pure tone audiometry in non-diabetic subjects.

2. To record pure tone audiometry in diabetic subjects.

3. To make a comparative study of the auditory acuity of type 2 diabetics and normoglycaemic subjects.

To analyse the effect of glycaemic status (FBS, PPBS), glycaemic control (HbA1c) and duration of type 2 diabetes on auditory acuity.

\section{METHODS}

Type of study - Case Control study, Sample size-100, 50 patients attending diabetic OPD and 50 non-diabetic patients attending medical OPD for some other illness. Type 2 diabetic patients between the ages 35 and 55 years and who were non-hypertensive were included. After selecting appropriate samples for the study based on the inclusion and exclusion criteria, a detailed history was elicited and clinical examination done as per the clinical proforma. The necessary investigations were done as per the proforma. The auditory acuity of cases and controls were compared in relation to glycaemic status (FBS, PPBS), HbA1c and duration of DM and statistically analysed.

\section{KEYWORDS}

Type 2 Diabetes Mellitus, Sensorineural Hearing Loss, Glycaemic Status.

HOW TO CITE THIS ARTICLE: Arun Kumar S, Babu R, Sakthivel V, et al. Prevalence of sensorineural hearing loss in type 2 diabetic subjects and its correlation to glycaemic status and duration of diabetes mellitus. J. Evolution Med. Dent. Sci. 2016;5(28): 1456-1460, DOI: $10.14260 /$ jemds/2016/342

\section{INTRODUCTION}

Diabetes Mellitus (DM) refers to a group of common metabolic disorders that share the phenotype of hyperglycaemia. Depending on the aetiology of the DM, factors contributing to hyperglycaemia include reduced insulin secretion, decreased glucose utilization and increased glucose production. The metabolic dysregulation of diabetes is associated with secondary pathophysiologic changes in multiple organ system like eyes, kidneys, nerves, heart and blood vessels.

The chronic complications of DM affect many organ systems and are responsible for the majority of morbidity and mortality associated with the disease. These include vascular and non-vascular complications; vascular complication may be microvascular or macrovascular.

Sensorineural Hearing Loss (SNHL) results from lesions of the cochlea, eighth nerve or central auditory pathways. The diagnosis of a sensorineural pattern hearing loss is made through audiometry, which shows a significant hearing loss without the "air-bone gap" that is characteristic of conductive hearing disturbances.

Financial or Other, Competing Interest: None.

Submission 16-02-2016, Peer Review 14-03-2016,

Acceptance 19-03-2016, Published 07-04-2016.

Corresponding Author:

Dr. Arun Kumar $S$,

No. 239, Church Street,

Karaikal-609602,

Pondicherry State.

E-mail: avsarun.kkl@gmail.com

DOI: $10.14260 /$ jemds $/ 2016 / 342$
Hearing loss may be an under-recognized complication of diabetes. As diabetes is emerging in a rapid manner, the disease may become a more significant contributor to hearing loss.

Diabetics are susceptible to hearing problems, because this disease may damage the nerves and blood vessels of the inner ear. While the connection between diabetes and susceptibility to vision loss is well known, unfortunately the statistics of diabetes related hearing loss among diabetics is not. Far too many diabetics do not ask for a hearing test and thus live with undiagnosed hearing loss for quite some time.

Hence, this study is undertaken to find out prevalence of (Sensorineural hearing loss) SNHL in diabetics and to correlate with glycaemic status and duration of Diabetes Mellitus (DM).

\section{Inclusion Criteria [Control]}

Normal healthy subjects of either sex between 35 and 55 years and who were non-hypertensive were included.

\section{Inclusion Criteria [Case]}

Type 2 diabetic patients between the ages 35 and 55 years and who were non-hypertensive were included. Both groups were matched with respect to age and sex.

\footnotetext{
Exclusion Criteria [Control]

1. Hypertension.

2. Diabetes mellitus.

3. History of consumption of ototoxic drugs in the past.

4. History of ear surgeries performed in the past.
} 
5. History of ear infection in the past.

6. History of systemic viral infection.

7. History of recent infections in the nose, throat or ear.

8. Patients having a noise-induced hearing loss (As shown by pure tone audiometry at $4000 \mathrm{~Hz}$ ).

\section{Exclusion Criteria [Case]}

1. History of consumption of ototoxic drugs in the past.

2. History of ear surgeries performed in the past.

3. History of ear infections in the past.

4. History of systemic viral infection.

5. History of recent infections in the nose, throat or ear.

6. Patients having a noise-induced hearing loss (As shown by pure tone audiometry at $4000 \mathrm{~Hz}$ ).

\section{METHODOLOGY}

After selecting appropriate samples for the study based on the inclusion and exclusion criteria, a detailed history was elicited and clinical examination done as per the clinical proforma. The necessary investigations were done as per the proforma.

The auditory acuity of cases and controls were compared in relation to glycaemic status (FBS, PPBS), HbA1c and duration of DM and statistically analysed.

\section{Sex Incidence}

Majority of the patients were female that holds $72 \%$ when compared to male $28 \%$.

Hemanth $\mathrm{C} .{ }^{1}$ et al. in their study found out that females were more affected than males in the ratio 1.4:1.

Panchu P. ${ }^{2}$ et al. in their study found that females were more affected than males in the ratio 1.5:1.

\begin{tabular}{|c|c|c|c|c|c|}
\hline $\begin{array}{l}\text { Sl. } \\
\text { No. }\end{array}$ & Sex & $\begin{array}{l}\text { Case } \\
\text { (No.) }\end{array}$ & $\begin{array}{c}\text { Percentage } \\
(\%)\end{array}$ & $\begin{array}{c}\text { Control } \\
\text { (No.) }\end{array}$ & $\begin{array}{c}\text { Percentage } \\
(\%)\end{array}$ \\
\hline 1 & Male & 14 & 28 & 25 & 50 \\
\hline 2 & Female & 36 & 72 & 25 & 50 \\
\hline \multicolumn{2}{|c|}{ Total } & 50 & 100 & 50 & 100 \\
\hline \multicolumn{6}{|c|}{ Table 1: Distribution of Gender } \\
\hline
\end{tabular}

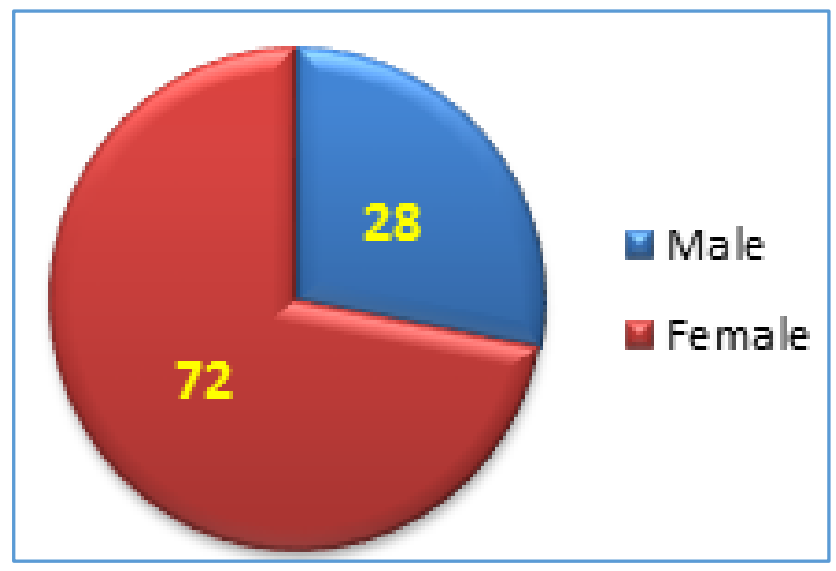

Fig. 1: Distribution of Gender

Our study was on par with the above studies.

\section{Age Incidence}

In the present study, the maximum number of patients with hearing loss were in the age group between 45 and 50 (58\%) followed by age group between 50 and 55 and was comparable with other studies.
Chyamal P.C. ${ }^{3}$ et al. in his study of vestibulo-cochlear functions in diabetes mellitus found out that the commonest age group that was affected was between 41 and 50 years (66$6 \%$ ) followed by age group between 31 and 40 years (25\%).

\begin{tabular}{|c|c|c|c|c|c|}
\hline $\begin{array}{c}\text { Sl. } \\
\text { No. }\end{array}$ & $\begin{array}{c}\text { Age Group } \\
\text { (Years) }\end{array}$ & Case & Percentage & Control & $\begin{array}{c}\text { Percentage } \\
\text { (\%) }\end{array}$ \\
\hline 1 & $35-40$ & 9 & 18 & 14 & 28 \\
\hline 2 & $41-45$ & 7 & 14 & 16 & 32 \\
\hline 3 & $46-50$ & 5 & 10 & 5 & 10 \\
\hline 4 & $51-55$ & 29 & 58 & 15 & 30 \\
\hline \multicolumn{7}{|c|}{ Total } & $\mathbf{5 0}$ & $\mathbf{1 0 0}$ & $\mathbf{5 0}$ & $\mathbf{1 0 0}$ \\
\hline
\end{tabular}

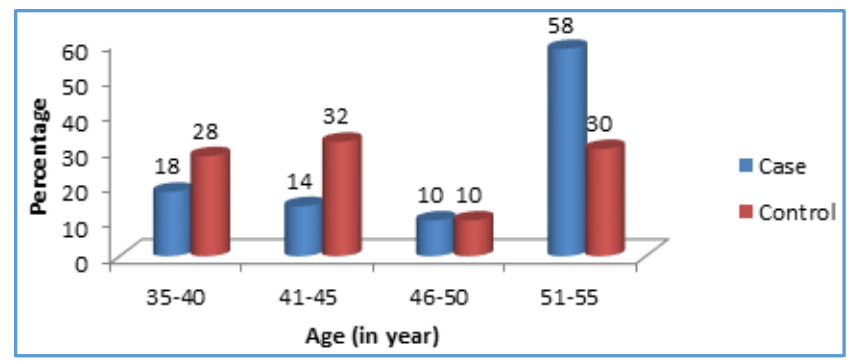

Fig. 2: Distribution of Age

Auditory threshold among cases and control

\begin{tabular}{|c|c|c|c|c|c|}
\hline \multirow{4}{*}{ Cases } & $\begin{array}{c}\text { Frequency } \\
\text { (Hz) }\end{array}$ & $\mathbf{3 5 - 4 0}$ & $\mathbf{4 0 - 4 5}$ & $\mathbf{4 5 - 5 0}$ & $\mathbf{5 0 - 5 5}$ \\
\cline { 2 - 6 } & 500 & 46 & 54 & 59 & 51 \\
\cline { 2 - 6 } & 1000 & 44 & 43 & 59 & 50 \\
\cline { 2 - 6 } & 2000 & 43 & 45 & 52 & 50 \\
\cline { 2 - 6 } & 4000 & 48 & 54 & 71 & 59 \\
\cline { 2 - 6 } & 8000 & 50 & 60 & 77 & 69 \\
\hline \multirow{4}{*}{ Control } & 500 & 38 & 42 & 44 & 55 \\
\cline { 2 - 6 } & 1000 & 38 & 43 & 48 & 57 \\
\cline { 2 - 6 } & 2000 & 38 & 43 & 51 & 60 \\
\cline { 2 - 6 } & 4000 & 40 & 49 & 50 & 63 \\
\hline & 8000 & 46 & 56 & 55 & 67 \\
\hline
\end{tabular}

Table 3: Auditory Threshold (in $\mathrm{dB}$ ) in different Age Groups (in years) among Cases and Control

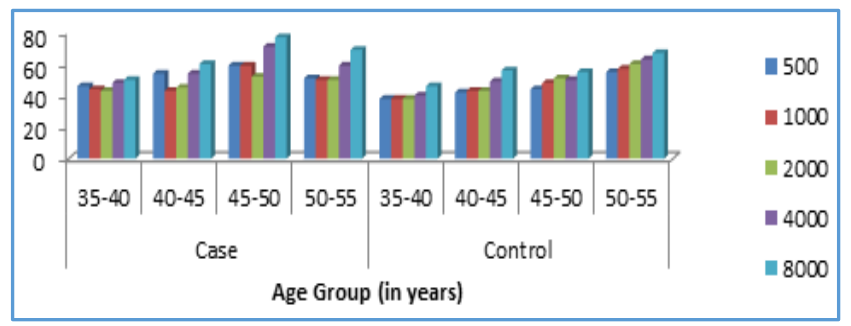

Fig. 3: Auditory Threshold in different Age Groups (in years) among Cases and Control

It was observed that the auditory threshold in different age group among cases and control clearly shows that the maximum threshold level was in cases when compared to control.

\section{Type of Hearing Loss in Diabetes Mellitus}

In present study, the hearing loss was predominantly bilateral and of sensorineural type affecting the higher frequencies. 
Kurien M. ${ }^{4}$ et al. in their study said that hearing loss in diabetic patients were mild-to-moderate and more in higher frequencies.

Cullen J.R. ${ }^{5}$ et al. in their study said that diabetic patients were significantly deafer than normal population and the hearing loss affected higher frequencies in both sexes.

Viratnimie. ${ }^{6}$ et al. in his study said that hearing levels tend to be worse in diabetic patients than in normal individuals and the difference was statistically significant in higher frequencies $(6000 \mathrm{~Hz}$ and $8000 \mathrm{~Hz})$.

Chyamal P.C. ${ }^{3}$ et al. in his study said that hearing loss in diabetes mellitus was bilateral, symmetrical and sensorineural and majority showing a loss more in higher frequencies.

Duck S.W. ${ }^{7}$ et al. in his study said that diabetes mellitus in conjunction with hypertension had a synergistic effect frequency sensorineural hearing loss.

Kutty S.R. ${ }^{8}$ et al. in his study opined that diabetics suffered from bilateral sensorineural type of hearing loss. All patients with diabetes showed significant high frequency hearing loss.

Fangchao. ${ }^{9}$ et al. in his study said that high frequency hearing loss was common in diabetics.

Sharma D.R. ${ }^{10}$ et al. in his study said that hearing loss was found to be bilateral symmetrical and sensorineural in type.

Kakarlapudi V. ${ }^{11}$ et al. in his study said that prevalence of sensory neural hearing loss was higher in diabetic population than non-diabetics.

Naini A.S. ${ }^{12}$ et al. in his study said that there was a specific existence of a specific and distinct hearing loss in high frequencies in diabetic patients.

Leon Morales L.V.D. ${ }^{13}$ et al. in their study said that type 2 diabetes mellitus is related to high frequency hearing loss.

Andriana.C. ${ }^{14}$ et al. in his study said that hearing loss in diabetic patients causes sensorineural hearing loss.

Our study correlated with all the above studies.

Hearing loss in Relation to Duration of Diabetes Mellitus

\begin{tabular}{|c|c|c|}
\hline $\begin{array}{c}\text { Frequency } \\
\text { (Hz) }\end{array}$ & \multicolumn{2}{|c|}{ Auditory Threshold in Cases (dB) } \\
\cline { 2 - 3 } & $\mathbf{5}$ years & > 5 years \\
\hline 500 & 49 & 55 \\
\hline 1000 & 48 & 53 \\
\hline 2000 & 47 & 55 \\
\hline 4000 & 54 & 65 \\
\hline 8000 & 63 & 67 \\
\hline \multicolumn{2}{|c|}{ Table 4: Auditory Threshold (dB) in Relation to } \\
Duration of Diabetics \\
\hline
\end{tabular}

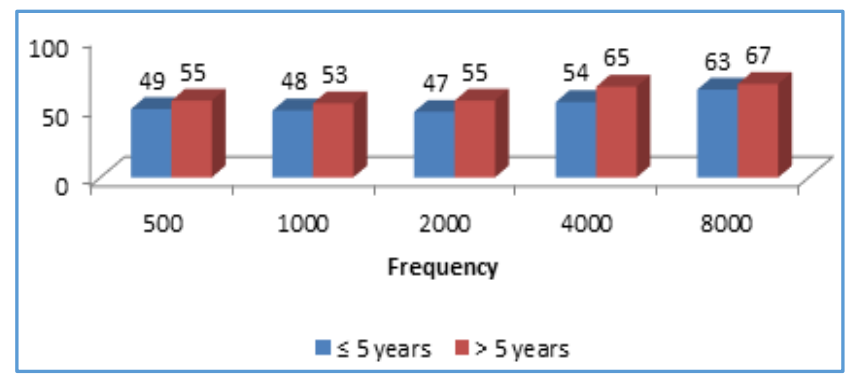

Fig. 4: Auditory Threshold (dB) in Relation to Duration of Diabetics
Similarly, in our study the auditory threshold in relation to duration of diabetic mellitus indicates that cases above 5 years of duration had increased auditory threshold.

Kurien M. et al. 1989 also indicated the same.

Chyamal P.C. ${ }^{3}$ et al. in his study said that there was no correlation found between hearing loss and duration of diabetes mellitus.

Dalton D.S. 15 et al. in their study found that there was no association between duration of diabetes mellitus and hearing loss.

Panchu P. ${ }^{2}$ et al. in her study said that there was no significant difference in hearing threshold between patients with short duration of type 2 diabetes mellitus versus long duration.

Auditory Threshold in Relation to Compliance to Treatment

\begin{tabular}{|c|c|c|}
\hline \multirow{2}{*}{$\begin{array}{c}\text { Frequency } \\
\text { (Hz) }\end{array}$} & Regular & Irregular \\
\hline 500 & 51 & 50 \\
\hline 1000 & 46 & 50 \\
\hline 2000 & 50 & 45 \\
\hline 4000 & 58 & 56 \\
\hline 8000 & 66 & 59 \\
\hline \multicolumn{2}{|c|}{ Table 5: Auditory Threshold (dB) in Relation to } \\
Compliance to Treatment in Diabetics \\
\hline
\end{tabular}

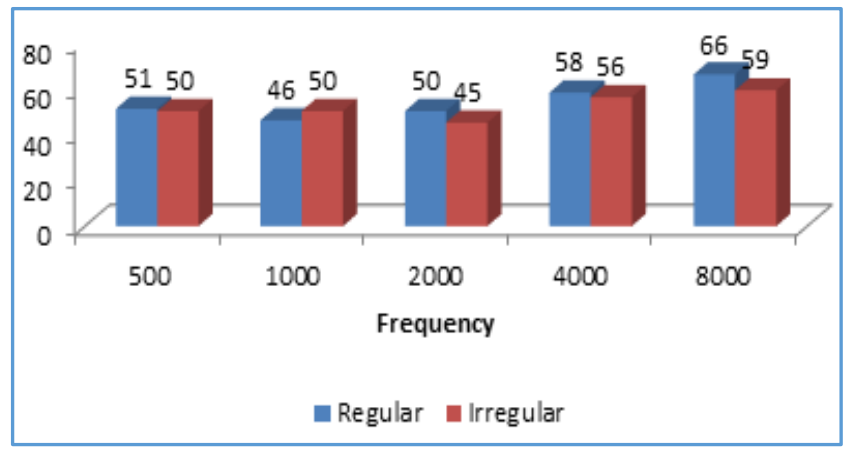

\section{Fig. 5: Auditory Threshold (dB) in Compliance to Treatment in Diabetics}

In our study, auditory threshold was found to be higher in patients to their compliance with treatment than in those who were not compliant.

Hemanth C. ${ }^{1}$ et al. 2006 has found that there was deterioration of hearing threshold in diabetic patients with uncontrolled DM.

\begin{tabular}{|c|c|c|c|}
\hline \multirow{2}{*}{$\begin{array}{c}\text { Frequency } \\
\text { (Hz) }\end{array}$} & \multicolumn{3}{|c|}{ dB } \\
\cline { 2 - 4 } OHA & Insulin & Both \\
\hline 500 & 49 & 47 & 59 \\
\hline 1000 & 49 & 50 & 55 \\
\hline 2000 & 49 & 45 & 53 \\
\hline 4000 & 57 & 55 & 60 \\
\hline 8000 & 64 & 55 & 65 \\
\hline \multicolumn{3}{|c|}{ Table 6: Auditory Threshold in Relation } \\
to Mode of Treatment \\
\hline
\end{tabular}




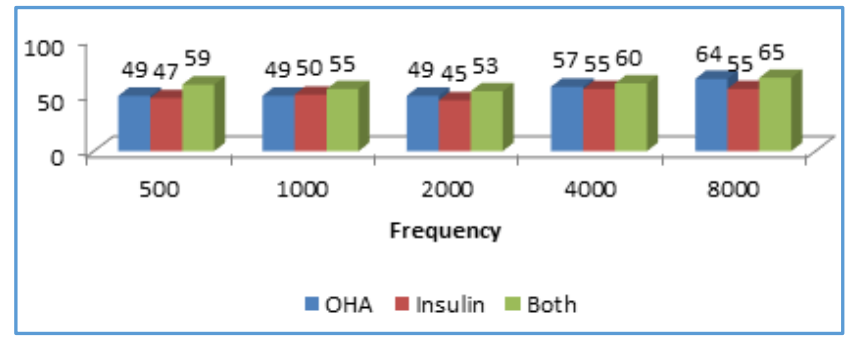

Fig. 6: Auditory Threshold in Relation to Mode of Treatment

\begin{tabular}{|c|c|c|c|c|c|}
\hline \multirow{2}{*}{$\begin{array}{c}\text { Frequency } \\
\text { (Hz) }\end{array}$} & \multicolumn{5}{|c|}{ dB } \\
\cline { 2 - 6 } & Smoking & Alcohol & Both & Tobacco & None \\
\hline 500 & 36 & 30 & 51 & 54 & 52 \\
\hline 1000 & 35 & 35 & 53 & 53 & 51 \\
\hline 2000 & 42 & 40 & 50 & 52 & 50 \\
\hline 4000 & 56 & 75 & 67 & 67 & 56 \\
\hline 8000 & 62 & 90 & 85 & 69 & 62 \\
\hline \multicolumn{7}{|c|}{ Table 7: Comparison of Auditory Threshold with } \\
Addictions \\
\hline
\end{tabular}

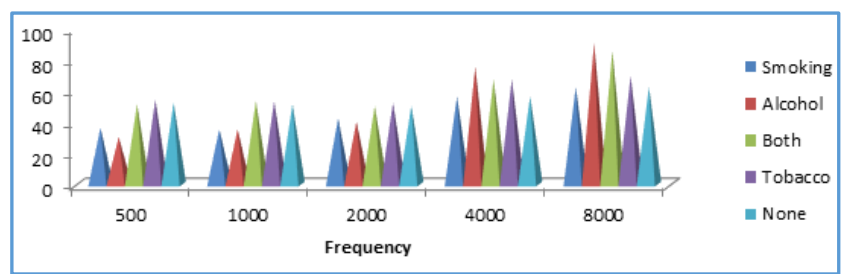

Fig. 7: Comparison of Auditory Threshold with Addictions

\begin{tabular}{|c|c|c|c|c|c|}
\hline \multirow{2}{*}{$\begin{array}{c}\text { Frequency } \\
\text { (Hz) }\end{array}$} & \multicolumn{5}{|c|}{ dB } \\
\cline { 2 - 6 } & $<\mathbf{1 0 0}$ & $\mathbf{1 0 0 - 1 2 5}$ & $\mathbf{1 2 6 - 1 5 0}$ & $\mathbf{1 5 1 - 2 0 0}$ & $>\mathbf{2 0 0}$ \\
\hline 500 & 50 & 56 & 46 & 53 & 53 \\
\hline 1000 & 56 & 53 & 47 & 48 & 50 \\
\hline 2000 & 58 & 53 & 49 & 45 & 47 \\
\hline 4000 & 69 & 58 & 58 & 53 & 56 \\
\hline 8000 & 79 & 68 & 63 & 60 & 64 \\
\hline \multicolumn{6}{|c|}{ Table 8: Auditory Threshold in Decibels } \\
at Various Levels of FBS \\
\hline
\end{tabular}

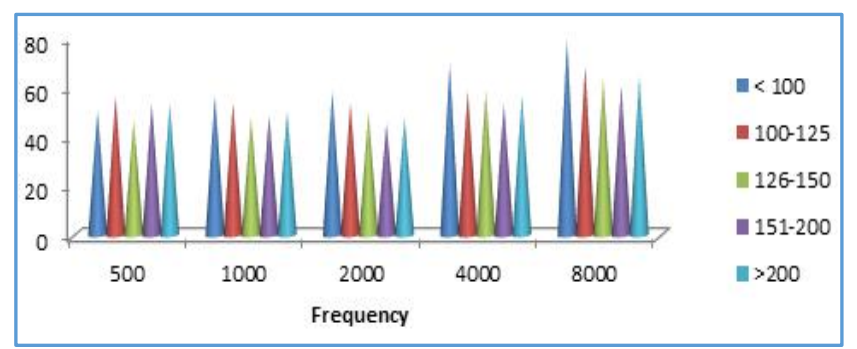

Fig. 8: Auditory Threshold in Decibels at Various Levels of FBS

\begin{tabular}{|c|c|c|c|c|c|}
\hline \multirow{2}{*}{ Frequency } & \multicolumn{5}{|c|}{ dB } \\
\cline { 2 - 6 } & $<\mathbf{4 0}$ & $\mathbf{1 4 0 - 2 0 0}$ & $\mathbf{2 0 1 - 3 0 0}$ & $\mathbf{3 0 1 - 4 0 0}$ & $>\mathbf{4 0 0}$ \\
\hline 500 & 45 & 43 & 57 & 54 & 47 \\
\hline 1000 & 53 & 43 & 57 & 49 & 46 \\
\hline 2000 & 50 & 42 & 59 & 45 & 46 \\
\hline 4000 & 75 & 52 & 66 & 57 & 52 \\
\hline 8000 & 95 & 57 & 73 & 64 & 61 \\
\hline \multicolumn{6}{|c|}{ Table 9: Auditory Threshold in Decibels } \\
at Various Levels of PPBS \\
\hline
\end{tabular}

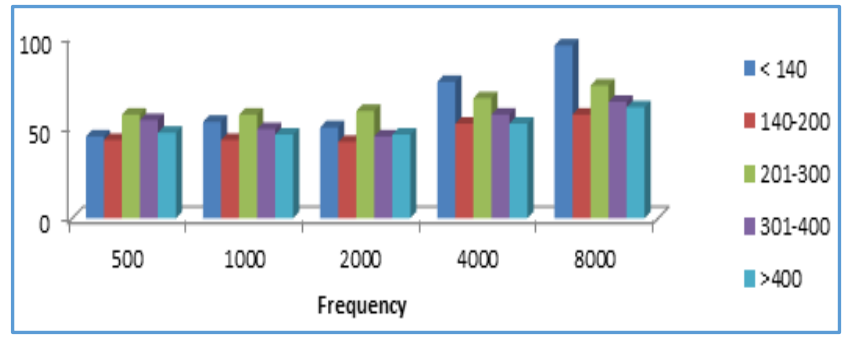

Fig. 9: Auditory Threshold in Decibels at Various Levels of PPBS

\begin{tabular}{|c|c|c|}
\hline \multirow{2}{*}{$\begin{array}{c}\text { Frequency } \\
\text { (Hz) }\end{array}$} & \multicolumn{2}{|c|}{ dB } \\
\cline { 2 - 3 } & $\mathbf{5 7}$ & $\mathbf{> 7}$ \\
\hline 500 & 50 & 53 \\
\hline 1000 & 48 & 52 \\
\hline 2000 & 48 & 53 \\
\hline 4000 & 57 & 60 \\
\hline 8000 & 64 & 69 \\
\hline \multicolumn{2}{|c|}{ Table 10: Auditory Threshold (dB) in Relation to } \\
Control of Diabetes Based on HbA1c \\
\hline
\end{tabular}

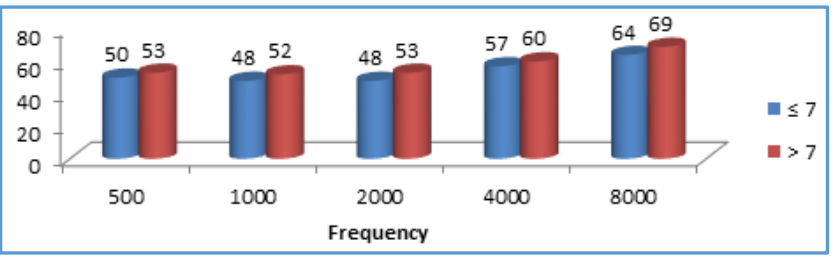

Fig. 10: Auditory Threshold (dB) in Relation to Control of Diabetes Based on HbA1c

\begin{tabular}{|c|c|c|c|c|}
\hline $\begin{array}{c}\text { Frequency } \\
\text { (Hz) }\end{array}$ & Macro-vascular & Micro-vascular & Both & None \\
\hline 500 & 45 & 57 & 45 & 52 \\
\hline 1000 & 43 & 55 & 55 & 50 \\
\hline 2000 & 43 & 50 & 60 & 51 \\
\hline 4000 & 53 & 68 & 70 & 58 \\
\hline 8000 & 61 & 81 & 100 & 64 \\
\hline \multicolumn{6}{|c}{ Table 11: Auditory Threshold and Complications } \\
\hline
\end{tabular}

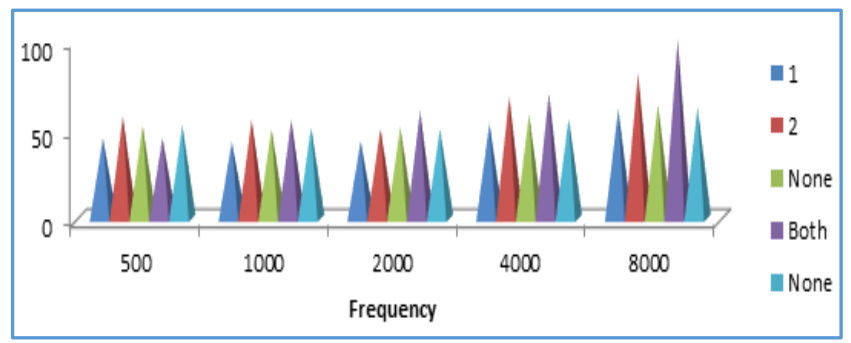

Fig. 11: Auditory Threshold and Complications

\section{CONCLUSION}

- Sensorineural hearing loss in diabetes mellitus, more commonly affected patients in the age group between 45 and 50 years accounting for $58 \%$.

- $72 \%$ of females were affected when compared to male (28\%).

- Comparison between cases and control revealed that the cases had increased auditory threshold.

- From this study it was found that there was a correlation between duration of diabetes mellitus and Sensorineural Hearing Loss (SNHL). 
- According to the data accumulated, there was a negative linear correlation between the compliance to treatment and people who had SNHL.

- In this study population, it was found that cases taking both OHA and Insulin had higher frequency of SNHL.

- Addictions to both smoking and alcohol were associated with a higher incidence of SNHL.

- Among the cases studied, there was a positive linear correlation between elevated PPBS and SNHL.

- Study population revealed a slightly higher incidence of developing SNHL in patients with HbA1c $>7$.

- Patients with SNHL had higher incidence of microvascular complication than macrovascular complications.

- Hearing impairment is an under-recognised complication of Diabetes Mellitus.

- Diabetes has been shown to affect hearing loss by many studies. Many have tried to identify the cause and based on their conclusion the probable mechanisms are microangiopathy of the inner ear, neuropathy of the cochlear nerve, a combination of both, outer hair dysfunction and disruption of endolymphatic potentials.

\section{REFERENCES}

1. Hemant C, Kapil D, Puneet B, et al. Cochlear changes in type II diabetes mellitus. Indian Journal of Otology 2006;12:3-10.

2. Pradhan AD, Manson JE, Rifai N, et al. C-reactive protein, interleukin 6 and risk of developing type 2 diabetes mellitus. JAMA 2001;286(3):327-334.

3. Chamyal PC. Vestibulo-cochlear functions in diabetes mellitus. Indian Journal of Otolaryngology Head Neck Surg 1997;49(2):162-164.

4. Kutty SR, Hazarika P, Rajshekar B, et al. Hearing loss in diabetes mellitus. Indian Journal of Otology 1998;4:131136.
5. Cullen JR, Cinnamond MJ, Ireland BN. Hearing loss in diabetics. The Journal of Laryngology and Otology 1993;107(3):179-182.

6. Weng SF, Chen YS, Hsu CJ, et al. Clinical features of sudden scnsorineural hearing loss in diabetic patients. Laryngoscope 2005;115((9):1676-1680.

7. Duck SW, Prazma J, Bennett PS, et al. Interaction between hypertension and diabetes mellitus in the pathogenesis of sensorineural hearing loss. Laryngoscope 1997;107(121):1596-1605.

8. Leon VD, Jauregui-Renaud K, Garay-Sevilla ME, et al. Auditory impairment in patients with type 2 diabetes mellitus. Archives of Medical Research 2005;36(5):507510.

9. Fangchao MA, Gomez-Marin O, Lee DJ, et al. Diabetes and hearing impairment in Mexican American adults: a population-based study. The journal of Larygology and Otology 1998;112:835-839.

10. Smith LT, Raynor E, Prazma J, et al. Insulin-dependent diabetic microangiopathy in the inner ear. Laryngoscope 1995;105(3):236-240.

11. Kurien M, Thomas K, Bhanu TS. Hearing threshold in patients with diabetes mellitus. Journal of Laryngology and Otology 1989;103(2):164-168.

12. Panchu P. Auditory acuity in type II diabetes mellitus. Int J Diab Dev Ctries 2008;28(4):114-120.

13. Maggi S, Minicuci N, Martini A, et al. Prevalence rates of hearing impairment and comorbid conditions in older people: the veneto study. Journal of the American Geriatrics Society 1998;46(9):1069-1074.

14. Adriana CS, Alberto CH. Diabetes mellitus as etiological factor of hearing loss. Rev Bras Otorrinolaringol 2005;71(2):2-8.

15. Dalton DS, Cruickshanks KJ, Klein R, et al. Assocation of NIDDM and hearing loss. Diabetes care 1998;21(9):15401544. 